
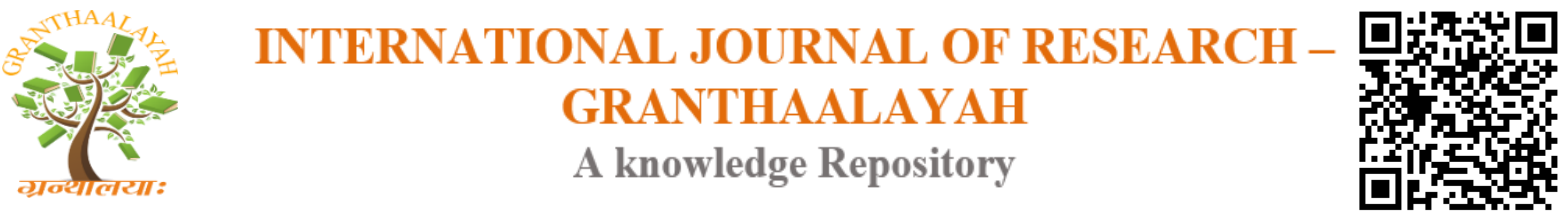

Science

\title{
ENHANCED SEEKER OPTIMIZATION ALGORITHM FOR REDUCTION OF ACTIVE POWER LOSS
}

\author{
Dr.K.Lenin *1 \\ ${ }^{* 1}$ Professor Prasad V. Potluri Siddhartha Institute of Technology Kanuru, Vijayawada, Andhra \\ Pradesh -520007, India
}

\begin{abstract}
This paper projects Enhanced Seeker Optimization (ESO) algorithm for solving optimal reactive power problem. Seeker optimization algorithm (SOA) models the deeds of human search population based on their memory, experience, uncertainty reasoning and communication with each other. In Artificial Bee Colony (ABC) algorithm the colony consists of three groups of bees: employed bees, onlookers and scouts. All bees that are presently exploiting a food source are known as employed bees. The number of the employed bees is equal to the number of food sources and an employed bee is allocated to one of the sources. In this paper hybridization of the seeker optimization algorithm with artificial bee colony (ABC) algorithm has been done to solve the optimal reactive power problem. Enhanced Seeker Optimization (ESO) algorithm combines two different solution exploration equations of the $\mathrm{ABC}$ algorithm and solution exploration equation of the SOA in order to progress the performance of SOA and ABC algorithms. At certain period's seeker's location are modified by search principles obtained from the ABC algorithm, also it adjust the inter-subpopulation learning phase by using the binomial crossover operator. In order to evaluate the efficiency of proposed Enhanced Seeker Optimization (ESO) algorithm it has been tested in standard IEEE 57,118 bus systems and compared to other specified algorithms. Simulation results clearly indicate the best performance of the proposed Enhanced Seeker Optimization (ESO) algorithm in reducing the real power loss and voltage profiles are within the limits.
\end{abstract}

Keywords: Reactive Power; Transmission Loss; Enhanced Seeker; Optimization.

Cite This Article: Dr.K.Lenin. (2017). "ENHANCED SEEKER OPTIMIZATION ALGORITHM FOR REDUCTION OF ACTIVE POWER LOSS." International Journal of Research - Granthaalayah, 5(10), 336-347. 10.29121/granthaalayah.v5.i10.2017.2310.

\section{Introduction}

Optimal reactive power dispatch problem is one of the difficult optimization problems in power systems. The sources of the reactive power are the generators, synchronous condensers, capacitors, static compensators and tap changing transformers. The problem that has to be solved in a reactive power optimization is to determine the required reactive generation at various locations so as to optimize the objective function. Here the reactive power dispatch problem 
involves best utilization of the existing generator bus voltage magnitudes, transformer tap setting and the output of reactive power sources so as to minimize the loss and to maintain voltage stability of the system. It involves a nonlinear optimization problem. Various mathematical techniques have been adopted to solve this optimal reactive power dispatch problem. These include the gradient method [1, 2], Newton method [3] and linear programming [4-7].The gradient and Newton methods suffer from the difficulty in handling inequality constraints. To apply linear programming, the input- output function is to be expressed as a set of linear functions which may lead to loss of accuracy. Recently many global optimization techniques have been proposed to solve the reactive power flow problem [8-10]. This paper projects Enhanced Seeker Optimization (ESO) algorithm for solving optimal reactive power problem. Seeker optimization algorithm (SOA) models the deeds of human search population [11-16] based on their memory, experience, uncertainty reasoning and communication with each other. In Artificial Bee Colony (ABC) algorithm [17-23] the colony consists of three groups of bees: employed bees, onlookers and scouts. All bees that are presently exploiting a food source are known as employed bees. The number of the employed bees is equal to the number of food sources and an employed bee is allocated to one of the sources. In this paper hybridization of the seeker optimization algorithm with artificial bee colony (ABC) algorithm has been done to solve the optimal reactive power problem. Enhanced Seeker Optimization (ESO) algorithm combines two different solution exploration equations of the $\mathrm{ABC}$ algorithm and solution exploration equation of the SOA in order to progress the performance of SOA and $\mathrm{ABC}$ algorithms. At certain period's seeker's location are modified by search principles obtained from the ABC algorithm, also it adjust the inter-subpopulation learning phase by using the binomial crossover operator. In order to evaluate the efficiency of proposed Enhanced Seeker Optimization (ESO) algorithm it has been tested in standard IEEE 57,118 bus systems and compared to other specified algorithms. Simulation results clearly indicate the best performance of the proposed Enhanced Seeker Optimization (ESO) algorithm in reducing the real power loss and voltage profiles are within the limits.

\section{Objective Function}

\subsection{Active Power Loss}

The objective of the reactive power dispatch problem is to minimize the active power loss and can be written in equations as follows:

$\mathrm{F}=P_{L}=\sum_{\mathrm{k} \in \mathrm{Nbr}} \mathrm{g}_{\mathrm{k}}\left(\mathrm{V}_{\mathrm{i}}^{2}+\mathrm{V}_{\mathrm{j}}^{2}-2 \mathrm{~V}_{\mathrm{i}} \mathrm{V}_{\mathrm{j}} \cos \theta_{\mathrm{ij}}\right)$

Where F- objective function, $\mathrm{P}_{\mathrm{L}}$ - power loss, $\mathrm{g}_{\mathrm{k}}$ - conductance of branch, $\mathrm{V}_{\mathrm{i}}$ and $\mathrm{V}_{\mathrm{j}}$ are voltages at buses i,j, Nbr- total number of transmission lines in power systems.

\subsection{Voltage profile improvement}

To minimize the voltage deviation in PQ buses, the objective function $(\mathrm{F})$ can be written as: $\mathrm{F}=P_{L}+\omega_{\mathrm{v}} \times \mathrm{VD}$

Where VD - voltage deviation, $\omega_{v^{-}}$is a weighting factor of voltage deviation. 
And the Voltage deviation given by:

$\mathrm{VD}=\sum_{\mathrm{i}=1}^{\mathrm{Npq}}\left|\mathrm{V}_{\mathrm{i}}-1\right|$

Where Npq- number of load buses

\subsection{Equality Constraint}

The equality constraint of the problem is indicated by the power balance equation as follows:

$\mathrm{P}_{\mathrm{G}}=\mathrm{P}_{\mathrm{D}}+\mathrm{P}_{\mathrm{L}}$

Where $\mathrm{P}_{\mathrm{G}^{-}}$total power generation, $\mathrm{P}_{\mathrm{D}}$ - total power demand.

\subsection{Inequality Constraints}

The inequality constraint implies the limits on components in the power system in addition to the limits created to make sure system security. Upper and lower bounds on the active power of slack bus $\left(\mathrm{P}_{\mathrm{g}}\right)$, and reactive power of generators $\left(\mathrm{Q}_{\mathrm{g}}\right)$ are written as follows:

$\mathrm{P}_{\text {gslack }}^{\min } \leq \mathrm{P}_{\text {gslack }} \leq \mathrm{P}_{\text {gslack }}^{\max }$

$\mathrm{Q}_{\mathrm{gi}}^{\min } \leq \mathrm{Q}_{\mathrm{gi}} \leq \mathrm{Q}_{\mathrm{gi}}^{\max }, \mathrm{i} \in \mathrm{N}_{\mathrm{g}}$

Upper and lower bounds on the bus voltage magnitudes $\left(\mathrm{V}_{\mathrm{i}}\right)$ is given by:

$V_{i}^{\min } \leq V_{i} \leq V_{i}^{\max }, i \in N$

Upper and lower bounds on the transformers tap ratios $\left(\mathrm{T}_{\mathrm{i}}\right)$ is given by:

$\mathrm{T}_{\mathrm{i}}^{\mathrm{min}} \leq \mathrm{T}_{\mathrm{i}} \leq \mathrm{T}_{\mathrm{i}}^{\mathrm{max}}, \mathrm{i} \in \mathrm{N}_{\mathrm{T}}$

Upper and lower bounds on the compensators $\left(\mathrm{Q}_{\mathrm{c}}\right)$ is given by:

$\mathrm{Q}_{\mathrm{c}}^{\min } \leq \mathrm{Q}_{\mathrm{c}} \leq \mathrm{Q}_{\mathrm{C}}^{\max }, \mathrm{i} \in \mathrm{N}_{\mathrm{C}}$

Where $\mathrm{N}$ is the total number of buses, $\mathrm{N}_{\mathrm{g}}$ is the total number of generators, $\mathrm{N}_{\mathrm{T}}$ is the total number of Transformers, $\mathrm{N}_{\mathrm{c}}$ is the total number of shunt reactive compensators.

\section{Seeker Optimization Algorithm}

Seeker optimization algorithm (SOA) models the deeds of human search population based on their memory, experience, uncertainty reasoning and communication with each other. Therefore the individual of this population is called seeker or searcher. In the SOA, the total population is equally categorized into three subpopulations according to the directories of the seekers. All the seekers in the same subpopulation constitute a neighborhood which symbolizes the social component for the social sharing of information. Seeker $i$ has the following attributes: the current Position $x_{i}=\left(x_{i 1}, x_{i 2}, \ldots, x_{i D}\right)$, the dimension of the problem $\mathrm{D}$, the iteration number $t$, the personal best position $\mathrm{p}_{\mathrm{i} \text {,best }}$ so far, and the neighborhood best position $\mathrm{g}_{\text {best }}$ so far. The algorithm uses exploration direction and step length to update the positions of seekers. In the SOA, the search direction is determined by seeker's egotistic behaviour, altruistic behaviour and pro- 
activeness behaviour, while step length is given by ambiguity reasoning behaviour. Search direction $\alpha_{i j}$ and step length $\mathrm{d}_{\mathrm{ij}}$ are separately computed for each individual $i$ on each dimension $j$ at each iteration $t$, where $\alpha_{i j} \geq 0$ and $\mathrm{d}_{\mathrm{ij}} \in\{-1 ; 0 ; 1\}$. At each iteration the position of each seeker is modernized by:

$x_{i j}(t+1)=x_{i j}(t)+\alpha_{i j}(t) \cdot d_{i j}$

Where $\mathrm{i}=1,2, \ldots, \mathrm{SN} ; \mathrm{j}=1,2, . ., \mathrm{D}$ ( $\mathrm{SN}$ is the number of seekers). Also, at each iteration, the current positions of the poorest two individuals of each subpopulation are swapped with the best ones in each of the other two subpopulations, which are called inter-subpopulation learning.

Algorithm of Seeker optimization

Create SN positions uniformly and arbitrarily in the exploration space;

$\mathrm{t}=0$;

Appraise all the seekers and save the historical best position;

Repeat

Calculate search direction and step length for each

Seeker;

Modernize each seeker's position

Estimate all the seekers and save the historical best position;

Implement the inter-subpopulation learning operation;

$\mathrm{t}=\mathrm{t}+1$

Until $\mathrm{t}=\mathrm{T}_{\max }$

\subsection{Design of the Search Direction}

Seeker supportive behaviour types that are modeled are: egoistic, altruistic and pro-active behaviour. Seeker's behaviour is considered egoistic if he believes that he should go toward his personal best position $\mathrm{p}_{\mathrm{i} \text {;bes }}$ through intellectual learning. For reaching the desired goal, by altruistic behaviour, seekers want to communicate with each other and adjust their behaviors in response to other seekers in the same neighborhood region. If a seeker wants to alter his exploration direction and exhibit goal-directed behaviour according to his previous behaviour, then it is considered that his behaviour is pro-active. The expression for exploration direction $d_{i}$, which models these types of behaviour, for the $i^{\text {th }}$ seeker is:

$d_{i}=\omega \cdot \operatorname{sign}\left(p_{i, b e s t}-x_{i}\right)+r_{1} \cdot\left(g_{\text {best }}-x_{i}\right)+r_{2} \cdot\left(x_{i}(t 1)\right)-x_{i}(t 2)$

Where the function sign ( $)$ is a signum function on each dimension of the input vector, wis the inertia weight, $\mathrm{t}_{1}, \mathrm{t}_{2} \in\{\mathrm{t}, \mathrm{t}-1, \mathrm{t}-2\}, x(\mathrm{t} 1)$ and $x(\mathrm{t} 2)$ are the best and the worst positions in the set $x(t), x(t-1), x(t-2)$ respectively, and $r_{1}$ and $r_{2}$ are real numbers chosen consistently and arbitrarily in the range $[0,1]$. The balance between global and local exploration and exploitation is provided by reducing the value of inertia weight. Here, inertia weight is linearly decreased from 0.9 to 0.1 during a run. 


\subsection{Design of the Step Size}

Fuzzy reasoning is used to produce the step length because the uncertain reasoning of human searching. The ambiguity rule of intelligent search is described as "If $\{$ function value is small $\}$, then s search radius is small \}". The linear membership function was used for "step length". The vector $\mu_{i}$ which is the grade of membership from cloud model and fuzzy set theory needs to be planned in order to compute the step length. It is inverse proportional to the objective function value of $x_{i}$. Hence, the best position so far has the maximum $\mu_{\max }=1.0$, while other positions have a $\mu<1.0$, and the worst position so far has the minimum $\mu_{\min }$ The expression is presented as:

$\mu_{i}=\mu_{\max }-\frac{S-I_{i}}{S-1} \cdot\left(\mu_{\max }-\mu_{\min }\right)$

Where $S$ denotes the size of the subpopulation to which the seekers belong, $I_{i}$ is the sequence number of $x_{i}$ after sorting the objective function values in ascending order. Besides the vector $\mu_{i}$ we need to calculate vector $\delta_{i}$ by:

$\delta_{i}=\omega \cdot \operatorname{abs}\left(x_{\max }-x_{\min }\right)$

Where the absolute value of the input vector as the corresponding output vector is represented by the symbol $a b s(), x_{\max }$ and $x_{\min }$ are the positions of the best and the worst seeker in the subpopulation to which the $i^{\text {th }}$ seeker belongs, respectively. In order to introduce the arbitrariness in each variable and to progress the local search capability, the following equation is introduced to convert $\mu_{i}$ into a vector with elements as given by:

$\mu_{i j}=\operatorname{rand}\left(\mu_{i}, 1\right), j=1,2, \ldots, D$

The equation used for creating the step length $\alpha_{i}$ for $i^{\text {th }}$ seeker is:

$\alpha_{i}=\delta_{i} \cdot \sqrt{-1 n\left(\mu_{i}\right)}$

\section{Artificial Bee Colony Algorithm}

In Artificial Bee Colony (ABC) algorithm the colony of artificial bees consists of three groups of bees: employed bees, onlookers and scouts. All bees that are presently exploiting a food source are known as employed bees. The number of the employed bees is equal to the number of food sources and an employed bee is allocated to one of the sources. Each food source is a possible solution for the problem and the nectar amount of a food source signifies the quality of the solution represented by the fitness value. Onlookers are those bees that are waiting in the hive for the employed bees to share information about the food sources presently being exploited by them, while scouts are those bees that are penetrating for new food sources arbitrarily. The number of onlooker and employed bees is the same. Onlookers are assigned to a food source based on probability. Like the employed bees, onlookers compute a new solution from its food source. After certain number of cycles, if food source cannot be further developed, it is abandoned and swapped by arbitrarily generated food source. This is called exploration procedure and it is performed by the scout bees. Hence, employed and onlooker bees carry out exploitation procedure, while scout bees perform exploration. Short pseudo code of the ABC algorithm is given below: 
Initialize the population of solutions

Calculate the population

$t=0$;

Repeat

Employed bee phase

Compute probabilities for onlookers

Onlooker bee phase

Scout bee phase

Remember the best solution achieved so far

$t=t+1$;

Until $t=T_{\text {max }}$

In employed bee phase an update procedure is performed for each solution in order to produce a new-fangled solution:

$v_{i j}=x_{i j}+\operatorname{rand} .\left(x_{i j}-x_{k j}\right)$

Where $\mathrm{k}=1,2, . ., \mathrm{SN}, \mathrm{j}=1,2, . ., \mathrm{D}$ are arbitrarily chosen indexes, $\mathrm{k} \neq \mathrm{i}$, and rand is a random number between $[-1,1]$ (SN is the number of solutions, $\mathrm{D}$ is the dimension of the problem). Then, a grasping selection is done between $x_{i}$ and $v_{i}$, which completes the modernize process. The main dissimilarity between the employed bee phase and the onlooker bee phase is that every solution in the employed bee phase involves the update procedure, while only the selected solutions have the opportunity to update in the onlooker bee phase. An inactive solution refers to a solution that does not change over a certain number of generations. In scout bee phase one of the most sluggish solutions is selected and swapped by a new arbitrarily created solution.

\section{Enhanced Seeker Optimization Algorithm}

Enhanced Seeker Optimization (ESO) algorithm combines two different solution exploration equations of the Artificial Bee Colony (ABC) algorithm and solution exploration equation of the Seeker optimization algorithm (SOA) in order to progress the performance of SOA and ABC algorithms. Also, algorithm implements the modified inter-subpopulation learning using the binomial crossover operator. Therefore, Enhanced Seeker Optimization (ESO) algorithm has changed the phase of updating seeker's positions and inter-subpopulation learning phase. The initialization phase remained the same as in SOA. Excluding common control parameters (solution number and maximum number of iterations), the Enhanced Seeker Optimization (ESO) algorithm keeps control parameter Subpop $N$ (subpopulation number) from SOA, while it does not include any other control parameter from the ABC algorithm. The introduced modifications are described as follows.

\subsection{Adjustment of Updating Seeker's Positions}

In the first 55\% of iterations the Enhanced Seeker Optimization (ESO) algorithm is searching for candidate solutions using exploration formula of $\mathrm{ABC}$ which is given by Eq. (16). After each candidate solution is formed and then appraised, its performance is compared with the old solution and a greedy selection mechanism is engaged as the selection operation between the old and the new candidate. If the new solution has better function value than the old candidate 
solution, it swaps the old one in the memory. In the continuing iterations, ESO chooses between search equation Eq. (10) which is used in SOA and the variant of ABC search equation which can be described as:

$v_{i j}=\left\{\begin{array}{c}x_{i j}+\operatorname{rand}_{i}\left(x_{i j}-x_{k j}\right), \text { if } R_{j}<0.5 \\ x_{i j}, \text { otherwise }\end{array}\right.$

Where $\mathrm{R}_{\mathrm{j}}$ is a random number within $[0,1), k$ is randomly chosen index from the whole population and has to be different from $i$, and $\operatorname{rand}_{i}$ is a random number between $[-1,1]$ and $j=$ $1,2, \ldots, \mathrm{D}$. The similar search equation is used in the $\mathrm{ABC}$ algorithm extended for constrained optimization problems, but the main difference is that in the Eq. (17) the value rand $_{i}$ is kept fixed for every $\mathrm{j}=1,2, \ldots, \mathrm{D}$. Also this modification is used in order to improve the ABC algorithm for the engineering optimization problems. The distinction between the Eq. (16) and the Eq. (17) is in the number of the optimization parameters which will be changed. In the basic $\mathrm{ABC}$, while producing a new solution, $v_{\mathrm{i}}$, changing only one parameter of the parent solution $x_{i}$ results in a slow convergence rate. In order to overcome this disadvantage, we set the probability of changing the optimization parameter to 0.5 . Also, in these iterations, the greedy selection mechanism is not used between the old and the new candidate solution. Hence, the diversity in the population is increased.

In the SOA search equation which is used in Enhanced Seeker Optimization (ESO) algorithm, the Eq. (13) for calculating vector $\delta_{i}$ is changed. It has been concluded that the vector $\delta$ is a sensitive parameter and that proposed calculation of its values was not suitable for optimization of multimodal functions. In order to overcome this obstacle, $\delta_{i}$ is calculated by:

$\delta=\omega \cdot \operatorname{abs}\left(x_{\max }-x_{\text {rand }}\right)$

Where $x_{\text {rand }}$ are the positions of the seekers in the same subpopulation where the solution $i$ belongs. Also, in order to further increase the diversity of the solutions, and the population, in the Enhanced Seeker Optimization (ESO) algorithm the inertia weight parameter $w$ is linearly decreased from 0.9 to 0.7 during a run.

The Enhanced Seeker Optimization (ESO) algorithm included a new control parameter which is called behavior rate $(B R)$ in order to select the exploration equation in the following way: if an arbitrary number between $[0,1]$ is less then $B R$ the SOA search equation is used, otherwise the Eq. (17) is performed.

\subsection{Modification of Inter-Subpopulation Learning}

In the modified inter-subpopulation learning the positions of seekers with the lowest objective function values of each subpopulation $l$ are united with the positions of seekers with the highest objective function values of $(1+\mathrm{t})$ mod Subpop $N$ subpopulations respectively, where $\mathrm{t}=1,2,3, .$. , NSC. NSC denotes the number of the worst seekers of each population which are combined with the best seekers. The appropriate seekers are united using the following binomial crossover operator as expressed in:

$x l_{n} j_{\text {worst }}=\left\{\begin{array}{c}x_{i_{j}}, \text { best }, \text { if } R_{j}<0.5 \\ x l_{n} j, \text { worst }, \text { otherwise }\end{array}\right.$ 
In Eq. (19) $R j$ is random number within [0,1],

$x l_{n} j_{\text {worst }}$ is denoted as the $j^{\text {th }}$ variable of the $n^{\text {th }}$ worst position in the $l^{\text {th }}$ sub population, $x_{i_{j}}$, best is the $j^{\text {th }}$ variable of the best position in the $i^{t h}$ subpopulation. It can be concluded that in the Enhanced Seeker Optimization (ESO) algorithm have two new control parameters in comparison with the original Seeker optimization algorithm (SOA): the behavior rate (BR) and the number of seekers of each subpopulation for combination (NSC). Behavior rate parameter controls which of the exploration equations for producing new population will be used. In the inter-subpopulation learning of SOA it has been noticed that it may not always bring the benefits for multimodal functions since it may attract all agents towards a local optimal solution. Hence, in order to provide better equilibrium between exploitation and exploration capabilities of the algorithm, the described modifications are introduced.

\section{Simulation Results}

Proposed Enhanced Seeker Optimization (ESO) algorithm has been tested in standard IEEE-57 bus power system. The reactive power compensation buses are 18, 25 and 53. Bus 2, 3, 6, 8, 9 and 12 are PV buses and bus 1 is selected as slack-bus. The system variable limits are given in Table 1.

The preliminary conditions for the IEEE-57 bus power system are given as follows:

$\mathrm{P}_{\text {load }}=12.012$ p.u. $\mathrm{Q}_{\text {load }}=3.016$ p.u.

The total initial generations and power losses are obtained as follows:

$\sum P_{G}=12.5042$ p.u. $\sum Q_{G}=3.3214$ p.u.

$\mathrm{P}_{\text {loss }}=0.25628$ p.u. $\mathrm{Q}_{\text {loss }}=-1.2012$ p.u.

Table 2 shows the various system control variables \& Table 3, gives the comparison of optimum results.

Table 1: Variable Limits

\begin{tabular}{|l|l|l|l|l|l|l|l|}
\hline \multicolumn{7}{|l|}{ Reactive Power Generation Limits } \\
\hline Bus no & 1 & 2 & 3 & 6 & 8 & 9 & 12 \\
\hline Qgmin & -1.4 & -.015 & -.02 & -0.04 & -1.3 & -0.03 & -0.4 \\
\hline Qgmax & 1 & 0.3 & 0.4 & 0.21 & 1 & 0.04 & 1.50 \\
\hline Voltage And Tap Setting Limits \\
\hline vgmin & Vgmax & vpqmin & Vpqmax & tkmin & tkmax \\
\hline 0.9 & 1.0 & 0.91 & 1.05 & 0.9 & 1.0 \\
\hline Shunt Capacitor Limits & & & \\
\hline Bus no & 18 & 25 & 53 & & \\
\hline Qcmin & 0 & 0 & 0 & & \\
\hline Qcmax & 10 & 5.2 & 6.1 & & \\
\hline
\end{tabular}

Table 2: Control variables obtained after optimization

\begin{tabular}{|l|l|}
\hline Control Variables & ESO \\
\hline V1 & 1.1 \\
\hline V2 & 1.038 \\
\hline V3 & 1.047 \\
\hline V6 & 1.036 \\
\hline
\end{tabular}




\begin{tabular}{|l|l|}
\hline V8 & 1.031 \\
\hline V9 & 1.018 \\
\hline V12 & 1.024 \\
\hline Qc18 & 0.0659 \\
\hline Qc25 & 0.201 \\
\hline Qc53 & 0.0450 \\
\hline T4-18 & 1.010 \\
\hline T21-20 & 1.058 \\
\hline T24-25 & 0.879 \\
\hline T24-26 & 0.811 \\
\hline T7-29 & 1.050 \\
\hline T34-32 & 0.882 \\
\hline T11-41 & 1.023 \\
\hline T15-45 & 1.040 \\
\hline T14-46 & 0.910 \\
\hline T10-51 & 1.020 \\
\hline T13-49 & 1.060 \\
\hline T11-43 & 0.910 \\
\hline T40-56 & 0.900 \\
\hline T39-57 & 0.950 \\
\hline T9-55 & 0.950 \\
\hline
\end{tabular}

Table 3: Comparison results

\begin{tabular}{|l|l|l|l|l|}
\hline S.No. & Optimization Algorithm & Finest Solution & Poorest Solution & Normal Solution \\
\hline 1 & NLP [24] & 0.25902 & 0.30854 & 0.27858 \\
\hline 2 & CGA [24] & 0.25244 & 0.27507 & 0.26293 \\
\hline 3 & AGA [24] & 0.24564 & 0.26671 & 0.25127 \\
\hline 4 & PSO-w [24] & 0.24270 & 0.26152 & 0.24725 \\
\hline 5 & PSO-cf [24] & 0.24280 & 0.26032 & 0.24698 \\
\hline 6 & CLPSO [24] & 0.24515 & 0.24780 & 0.24673 \\
\hline 7 & SPSO-07 [24] & 0.24430 & 0.25457 & 0.24752 \\
\hline 8 & L-DE [24] & 0.27812 & 0.41909 & 0.33177 \\
\hline 9 & L-SACP-DE [24] & 0.27915 & 0.36978 & 0.31032 \\
\hline 10 & L-SaDE [24] & 0.24267 & 0.24391 & 0.24311 \\
\hline 11 & SOA [24] & 0.24265 & 0.24280 & 0.24270 \\
\hline 12 & LM [25] & 0.2484 & 0.2922 & 0.2641 \\
\hline 13 & MBEP1 [25] & 0.2474 & 0.2848 & 0.2643 \\
\hline 14 & MBEP2 [25] & 0.2482 & 0.283 & 0.2592 \\
\hline 15 & BES100 [25] & 0.2438 & 0.263 & 0.2541 \\
\hline 16 & BES200 [25] & 0.3417 & 0.2486 & 0.2443 \\
\hline 17 & Proposed ESO & 0.22102 & 0.23118 & 0.22134 \\
\hline
\end{tabular}

Proposed Enhanced Seeker Optimization (ESO) algorithm has been tested in standard IEEE 118bus test system [26].The system has 54 generator buses, 64 load buses, 186 branches and 9 of them are with the tap setting transformers. The limits of voltage on generator buses are 0.95-1.1 
per-unit., and on load buses are 0.95-1.05 per-unit. The limit of transformer rate is 0.9-1.1, with the changes step of 0.025 . The limitations of reactive power source are listed in Table 4 , with the change in step of 0.01 .

Table 4: Limitation of reactive power sources

\begin{tabular}{|l|l|l|l|l|l|l|l|}
\hline BUS & 5 & 34 & 37 & 44 & 45 & 46 & 48 \\
\hline QCMAX & 0 & 14 & 0 & 10 & 10 & 10 & 15 \\
\hline QCMIN & -40 & 0 & -25 & 0 & 0 & 0 & 0 \\
\hline BUS & 74 & 79 & 82 & 83 & 105 & 107 & 110 \\
\hline QCMAX & 12 & 20 & 20 & 10 & 20 & 6 & 6 \\
\hline QCMIN & 0 & 0 & 0 & 0 & 0 & 0 & 0 \\
\hline
\end{tabular}

The statistical comparison results have been list in Table 5 and the results clearly show the better performance of proposed Enhanced Seeker Optimization (ESO) algorithm.

Table 5: Comparison results

\begin{tabular}{|l|l|l|l|l|}
\hline Active power loss (MW) & $\begin{array}{l}\text { BBO } \\
{[\mathbf{2 7}]}\end{array}$ & $\begin{array}{l}\text { ILSBBO/ } \\
\text { strategy1 } \\
{[\mathbf{2 7}]}\end{array}$ & $\begin{array}{l}\text { ILSBBO/ } \\
\text { strategy1 } \\
{[\mathbf{2 7}]}\end{array}$ & $\begin{array}{l}\text { Proposed } \\
\text { ESO }\end{array}$ \\
\hline Min & 128.77 & 126.98 & 124.78 & 116.32 \\
\hline Max & 132.64 & 137.34 & 132.39 & 122.74 \\
\hline Average & 130.21 & 130.37 & 129.22 & 118.46 \\
\hline
\end{tabular}

\section{Conclusion}

In this paper Enhanced Seeker Optimization (ESO) algorithm successfully solved the optimal reactive power problem. Enhanced Seeker Optimization (ESO) algorithm combines two different solution exploration equations of the $\mathrm{ABC}$ algorithm and solution exploration equation of the Seeker optimization algorithm (SOA) in order to progress the performance of SOA \& Artificial Bee Colony (ABC) algorithm. At certain period's seeker's location are modified by search principles obtained from the $\mathrm{ABC}$ algorithm, also it adjust the inter-subpopulation learning phase by using the binomial crossover operator. In order to evaluate the efficiency of proposed Enhanced Seeker Optimization (ESO) algorithm it has been tested in standard IEEE 57,118 bus systems and compared to other specified algorithms. Simulation results clearly indicate the best performance of the proposed Enhanced Seeker Optimization (ESO) algorithm in reducing the real power loss and voltage profiles are within the limits.

\section{References}

[1] O.Alsac, B. Scott, "Optimal load flow with steady state security”, IEEE Transaction. PAS -1973, pp. 745-751.

[2] Lee K Y ,Paru Y M , Oritz J L -A united approach to optimal real and reactive power dispatch , IEEE Transactions on power Apparatus and systems 1985: PAS-104 : 1147-1153

[3] A. Monticelli , M .V.F Pereira, and S. Granville, "Security constrained optimal power flow with post contingency corrective rescheduling", IEEE Transactions on Power Systems :PWRS-2, No. 1, pp.175-182.,1987. 
[4] Deeb N, Shahidehpur S.M, Linear reactive power optimization in a large power network using the decomposition approach. IEEE Transactions on power system 1990: 5(2) : 428-435

[5] E. Hobson ,'Network consrained reactive power control using linear programming, ' IEEE Transactions on power systems PAS -99 (4) ,pp 868-877, 1980

[6] K.Y Lee, Y.M Park, and J.L Oritz, "Fuel -cost optimization for both real and reactive power dispatches", IEE Proc; 131C, (3), pp.85-93.

[7] M.K. Mangoli, and K.Y. Lee, "Optimal real and reactive power control using linear programming”, Electr.Power Syst.Res, Vol.26, pp.1-10,1993.

[8] Berizzi.C.Bovo,M.Merlo,and M.Delfanti,(2012), "A GA approach to compare ORPF objective functions including secondary voltage regulation,” Electric Power Systems Research, vol. 84, no. 1 , pp. $187-194$.

[9] D. Devaraj, and B. Yeganarayana, "Genetic algorithm based optimal power flow for security enhancement", IEE proc-Generation.Transmission and. Distribution; 152, 6 November 2005.

[10] C.A. Caviars, A.C.Z.de Souza and V.H. Quintana, "Comparison of performance indices for detection of proximity to voltage collapse," vol. 11. no.3, pp.1441-1450, Aug 1996.

[11] C. Dai, Y. Zhu, W. Chen: Seeker Optimization Algorithm, Lecture Notes in Computer Science, 4456, 167-176 (2007)

[12] C. Dai, W. Chen, Y. Song, Y. Zhu: Seeker optimization algorithm: a novel stochastic search algorithm for global numerical optimization, Journal of Systems Engineering and Electronics, 21(2), 300-311 (2010)

[13] C. Dai, W. Chen, Y. Zhu, Z. Jiang, Z. You: Seeker optimization algorithm for tuning the structure and parameters of neural networks, Neurocomputing, 74(6), 876-883 (2011)

[14] C. Dai, W. Chen, Y. Zhu: Seeker optimization algorithm for digital IIR filter design, IEEE Transactions on Industrial Electronics, 57(5), 1710-1718 (2010)

[15] C. Dai, Z. Cheng, Q. Li, Z. Jiang, J. Jia: Seeker optimization algorithm for global optimization: A case study on optimal modelling of proton exchange membrane fuel cell (PEMFC), International Journal of Electrical Power and Energy Systems, 33(3), 369-376 (2011)

[16] C. Dai, W. Chen, L. Ran, Y. Zhang, Y. Du: Human Group Optimizer with Local Search, Lecture Notes in Computer Science, 6728, 310-320 (2011)

[17] D. Karaboga, B. Basturk: A powerful and efficient algorithm for numerical function optimization: Artificial bee colony (abc) algorithm, Journal of Global Optimization, 39(3), 459- 471 (2007)

[18] N. Bacanin, M. Tuba: Artificial Bee Colony (ABC) Algorithm for Constrained Optimization Improved with Genetic Operators, Studies in Informatics and Control, 21(2), 137-146 (2012)

[19] I.Brajevic, M. Tuba: An upgraded artificial bee colony algorithm (ABC) for constrained optimization problems, Journal of Intelligent Manufacturing, published Online First, DOI: 10.1007/s10845-011-0621-6, (2012)

[20] I. Brajevic, M. Tuba, M. Subotic: Performance of the improved artificial bee colony algorithm on standard engineering constrained problems, International Journal of Mathematics and Computers in Simulation, 5(2), 135-143 (2011)

[21] N. Stanarevic, M. Tuba, N. Bacanin: Modified artificial bee colony algorithm for constrained problems optimization, International Journal of Mathematical Models and Methods in Applied Sciences, 5(3), 644-651 (2011)

[22] N. Bacanin, M. Tuba, I. Brajevic: Performance of objectoriented software system for improved artificial bee colony optimization, International Journal of Mathematics and Computers in Simulation, 5(2), 154-162 (2011)

[23] M. Subotic, M. Tuba, N. Stanarevic: Different approaches in parallelization of the artificial bee colony algorithm, International Journal of Mathematical Models and Methods in Applied Sciences, 5(4), 755-762 (2011).

[24] Chaohua Dai, Weirong Chen, Yunfang Zhu, and Xuexia Zhang, "Seeker optimization algorithm for optimal reactive power dispatch,” IEEE Trans. Power Systems, Vol. 24, No. 3, August 2009, pp. 1218-1231. 
[25] J. R. Gomes and 0. R. Saavedra, "Optimal reactive power dispatch using evolutionary computation: Extended algorithms," IEE Proc.-Gener. Transm. Distrib.. Vol. 146, No. 6. Nov. 1999.

[26] IEEE, "The IEEE 30-bus test system and the IEEE 118-test system", (1993), http://www.ee.washington.edu/trsearch/pstca/.

[27] Jiangtao Cao, Fuli Wang and Ping Li, "An Improved Biogeography-based Optimization Algorithm for Optimal Reactive Power Flow", International Journal of Control and Automation Vol.7, No.3 (2014), pp.161-176.

*Corresponding author.

E-mail address: gklenin@ gmail.com 